\title{
Metrology in an ISO 15189 accredited medical biology laboratory
}

\author{
C. Guichet ${ }^{1,2, \star}$ and S. Pellegrinelli ${ }^{2}$
}

1 PROCORAD Association, Commissariat à L'Énergie Atomique et aux Énergies Alternatives (French Atomic Energy and Alternative Energies Commission), Bureau du Conseiller Médical (Medical Advisor's Office) MR/CM BP 1692265 Fontenay aux Roses Cedex, France

2 CEA DAM Laboratoire de Biologie Médicale (Medical Biology Laboratory), Île-de-France Bruyères le Châtel 91297 Arpajon Cedex, France

Received: 11 March 2014 / Accepted: 17 June 2014

\begin{abstract}
All French medical biology laboratories must be accredited according to ISO 15189 for all tests conducted. Metrology is therefore critical and covers a wide variety of areas. This presentation will focus on the metrology manager's role which is tailored to the medical biology laboratory: human resources in place, methods used, parameters followed, equipment used and strategies implemented when using equipment which is not connected to the International System of Units. It will be illustrated by examples of in vitro and in vivo clinical biochemistry, biological haematology, human toxicology and radiotoxicology. The presentation will cover the exploitation of results of internal controls and interlaboratory comparisons in order to calculate uncertainties and provide doctors with a result along with an interpretation or opinion to ensure optimum patient care. The conclusion will present the steps carried out at the Laboratoire National d'Essai (French National Testing Laboratory) to provide medical biology laboratories with certified clinical biology standards.
\end{abstract}

Keywords: Metrology, medical biology, intercomparisons, radiotoxicology, toxicology, ISO 15189 standard

\section{Introduction}

Medical biology laboratories (MBL) produce large amounts of data used for diagnosis and specification of treatment. Providing doctors and patients with results that are sufficiently precise and reliable is a key challenge for MBLs. Analysis instrument control has become essential since the early 2000s through the implementation of the GBEA [1] and more recently the introduction of the law of 30 May 2013 [2] reforming medical biology and requiring mandatory accreditation according to standard NF EN ISO 15189 [3] for all analysis conducted in an MBL. Together with the regulatory environment, the growing and increasingly complex automation of instruments requires stringent organization through applying a quality management system and appointing a metrology manager in the laboratory.

There are an estimated several hundred routine analysis and quantities analysed in MBLs. The variety and complexity of matrices analysed increases the difficulty of analysis for MBLs. Outside of traditional metrology (scales, thermometer, pipettes, etc.) and with rare exceptions (radiotoxicology, toxicology), the metrology challenge within an accredited MBL is to ensure the traceability of analysis using the units of the International System of Units (SI).

^ Correspondence: claude.guichet@cea.fr
This article will describe the five components of metrological control in our medical biology laboratory.

- Human resources: the metrology manager's role.

- Technical methods and traceability medium.

- Materials, equipment and quantities monitored.

- Analytical performance control.

- Estimation of measurement uncertainty.

Each component will be illustrated with examples from our medical biology laboratory.

\section{The metrology function}

The complexity, variety and number of instruments used in the MBL require the metrology manager's role to be tailored to the situation. However, each member of the MBL carries out part of the metrology function, particularly where complex biochemistry and haematology instruments are concerned.

The setting up of the metrology function and the related responsibilities are mentioned in the GBEA [1], Chapter II.3 (Instrumentation): "The laboratory manager must ensure that the metrological means required for their usual verification are implemented", and defined in standard NF EN ISO 10012 [4]: "function which has the administrative and technical responsibility for defining and implementing the measurement management system". 
Standard NF EN ISO 10012 also states that the metrology function "must be defined by the organization" and that this function "may be carried out by a specific department or spread across the whole organization".

Our laboratory's implementation of standard NF EN ISO 15189 was guided by this standard. The MBL's management defined the responsibilities of the metrology function and appointed and authorized a metrology manager and the temporary replacements required to ensure the efficient operation of the measurement management system.

The metrology manager reports directly to the lead biologist. Like the MBL quality assurance manager, the metrology manager must directly consult the laboratory management who make decisions relating to the laboratory's policy and resources.

\subsection{Training}

The requirements of the GBEA, NF EN ISO 15189 and Cofrac document SH REF 02 [5] imposed the need for additional metrology training due to the inadequacy of university training of technicians in this field.

The MBL management set up a training programme with the relevant French organizations in order to authorize the technician appointed to carry out the role of metrology manager.

The first crucial stage was the provision of training relating to standard NF EN ISO/CEI 17025 [6], which is applicable to the MBL, with a view to gaining approval for organizations in charge of the individual monitoring of the exposure of personnel to ionising radiation. This was later followed by additional training relating to standard NF EN ISO 15189 to learn the specific requirements relating to metrology carried out in an MBL. This training was provided by an organization linked to the French Standards Association (AFNOR).

The technician approached to fulfil the metrology manager role completed three training courses in two years: "Pipette quality assurance and metrology", "Managing measuring equipment: connection between metrological technology and organization" and "Metrology basics: setting up, controlling and improving monitoring and measuring devices".

This training provided a basis for carrying out tutoring for authorizing temporary replacement staff.

At the same time, within the scope of in-service training, the metrology manager uses reference materials: French or international standards and metrology documentation applicable to the MBL.

The lead biologist, the metrology manager's substitute, completed training in validating laboratory methods and estimating measurement and test result uncertainty. The purpose of this training was to acquire the skills to produce validation or verification documentation for the different tests carried out in the MBL and to create the tools for the metrological monitoring of the different instruments in the MBL (pipettes, scales, automated biology systems, radioactivity measurement systems, etc.).
Technical personnel in charge of using the different measuring instruments also completed NF EN ISO/CEI 17025 and NF EN ISO 15189 standard awareness training. In-house metrological monitoring training is carried out in the form of tutoring by the metrology manager or the lead biologist. It is supplemented by on-site training which may be combined with training at the supplier's premises in the use, metrological monitoring or maintenance of large complex automated biology or radiotoxicology systems.

The MBL has basic metrological documents drawn up by the "Quality assurance and metrology" working group of the Société Française de Biologie Clinique and the Collège Français de Métrologie to maintain the metrology skills of all personnel.

Training is monitored with training certificates provided by the training organizations or supplier or the tutoring record at the workstation containing the different tutoring actions and stages, when they were carried out, the technician who completed them and the tutor who validated the stages. The tutoring stage is recorded for each member of staff. This document monitors the employee during their presence in the laboratory. It contains a record of all external training and the documentary references for each element.

\subsection{Maintenance of competence}

Standard NF EN ISO 15189 is a reference of requirements concerning not only the quality of the management system but also the competence of MBL personnel. The MBL had to put in place a process for maintaining the competence of its personnel as well as criteria for validating this competence. The laboratory management chose to monitor the maintenance of competence in the field of metrology in an indirect fashion. Conducting mini-exams or testing in any form would not be seen in a positive light by technical personnel.

Metrology skills and their maintenance are evaluated by two major actions: self-assessment carried out using external quality evaluations (Probioqual, Procorad, etc.) and annual internal and external audits during accreditation follow-up or renewal evaluation visits. The acceptance criteria for self-assessment are results within the acceptable limits defined by the regulations like in the case of blood lead levels [7], known standards for radiotoxicology [8] or by learned societies or publications [9-11] for the rest of biology.

The acceptance criteria for monitoring with internal audits is the absence of critical errors in the field of metrology.

\subsection{The metrology manager's responsibilities}

In our MBL, each member of staff has a job sheet (Fig. 1) listing the functions (activities for which the person is integrated into the MBL team) and the responsibilities (cross-functional activities required for the operation of 


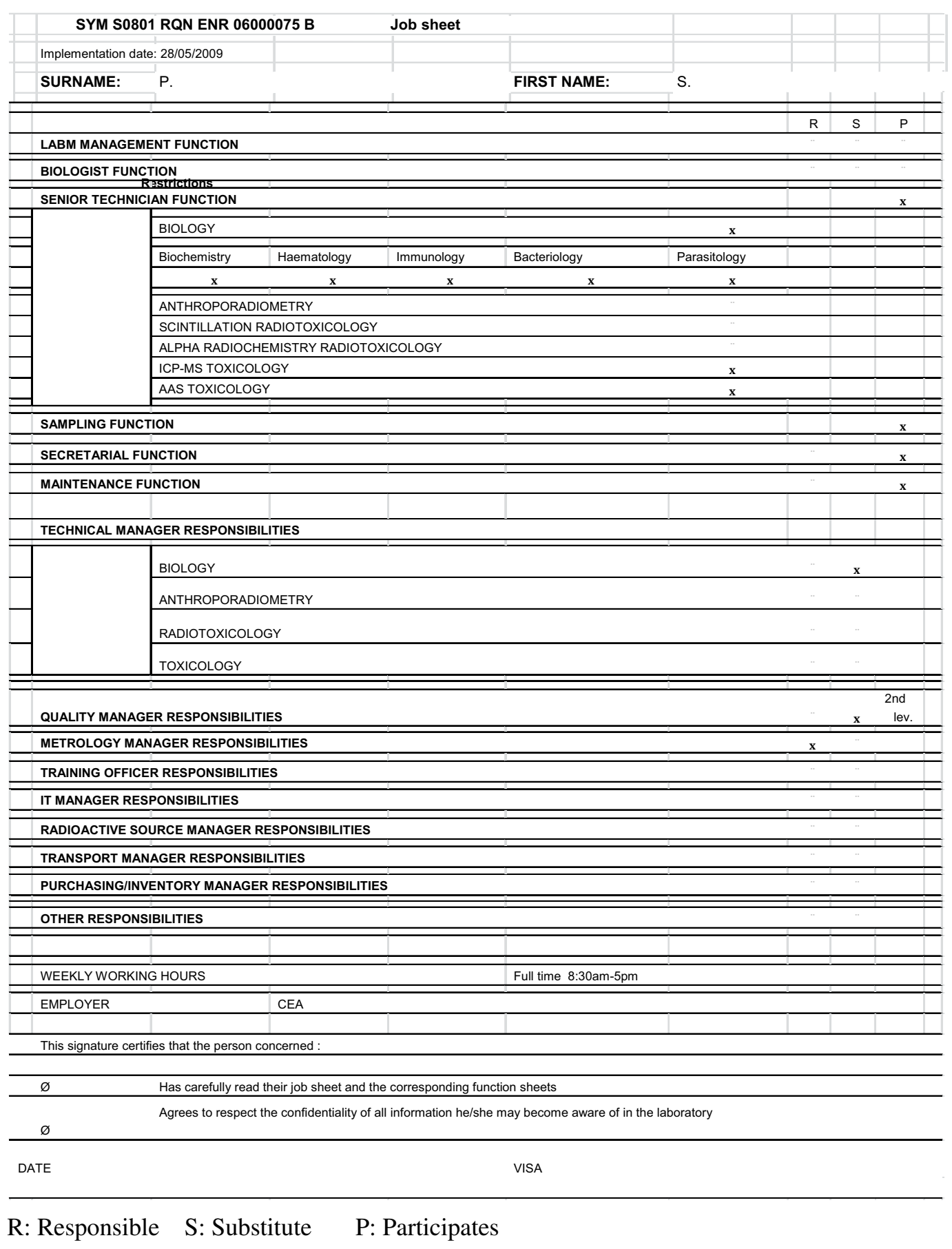

Fig. 1. Job sheet.

the MBL or the accomplishment of tasks requested by the CEA management), including those of the metrology manager. The functions and responsibilities are described in a document (internal memo) which also includes all the MBL's temporary substitutes and the organisation chart.

The MBL's internal memo describes the metrology manager's role: "manage the measuring instruments and devices". This role is carried out in close collaboration with the lead biologist. The role involves the following: being responsible for the external maintenance of devices, measuring instruments and small appliances particularly by managing the monitoring of external calibration certificates drawn up by subcontractors accredited by Cofrac or an organisation recognised by Cofrac; being responsible for regularly checking devices, measuring instruments and small appliances, monitoring the external maintenance, calibration and verification programme for devices, measuring instruments and small appliances. The metrology manager draws up the procedures, operating procedures and instructions concerning the metrological monitoring of devices, measuring instruments and small appliances. 


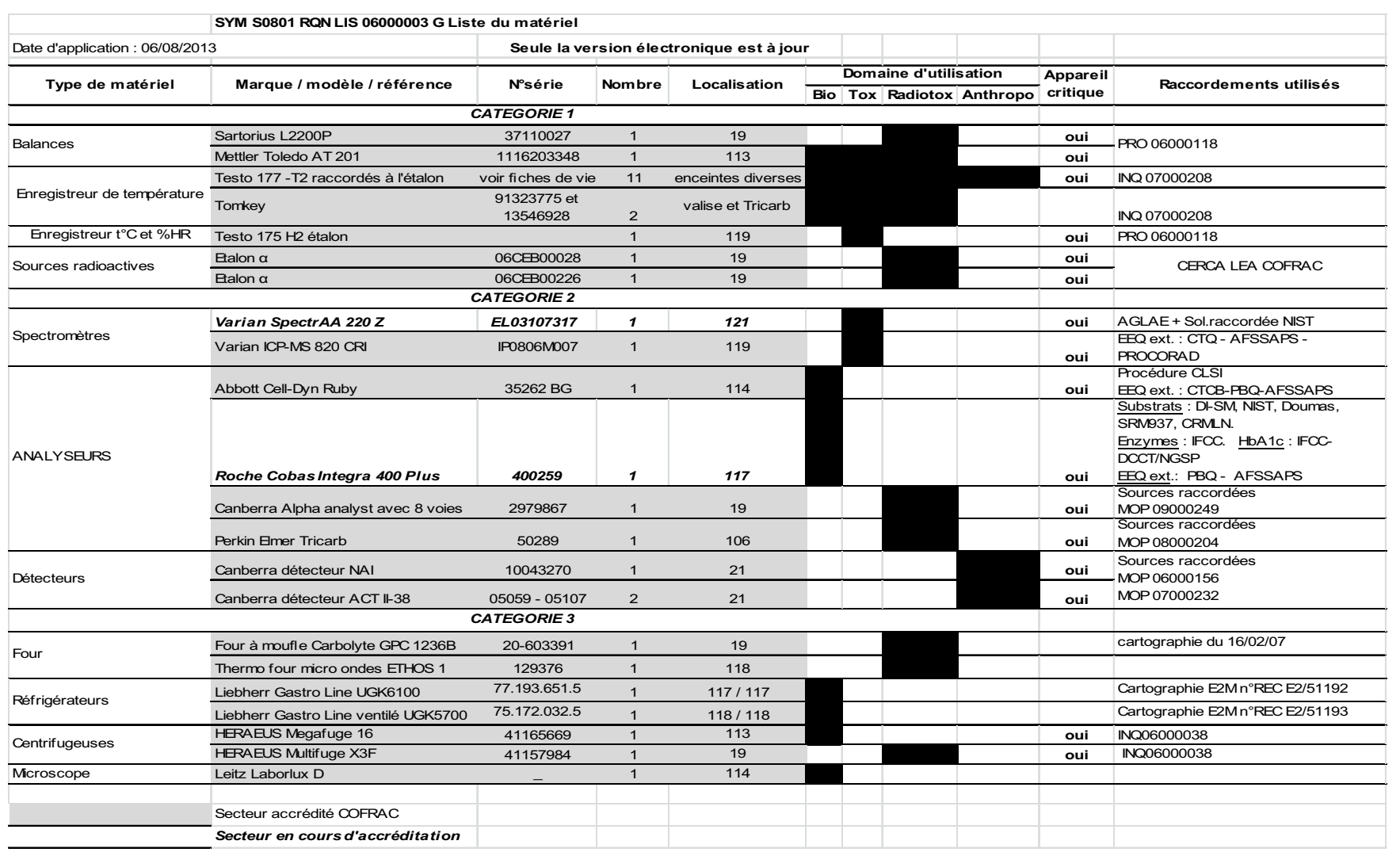

Fig. 2. Equipment list.

These activities correspond to what is described in standard NF EN ISO 10012.

\section{Setting up the metrology function}

The biologist initiated setting up the metrology function after approving the authorization of the metrology manager. At the same time, consideration was already being given to drawing up an inventory of devices, measuring instruments and small appliances in the MBL. This inventory enabled the instruments and the related standards to be put into a metrological hierarchy with 3 categories as described in the MBL procedure "Control of measuring and test equipment". Category 1 includes measuring equipment which provides results which can be directly linked to national or international standards via an unbroken chain. This category includes equipment and related standards: scales and weights, thermometers and hygrometers, pipettes, chronometers, radioactive sources and standard metal solutions. Category 2 represents analysis equipment which uses relative or absolute methods and which provides results which cannot be directly linked to national standards: spectrometers, $\mathrm{pH}$ meters.

By extension, the MBL has associated the following with category 2 : reference materials whether or not certified and the reagents considered as such, automated biochemistry and haematology systems, atomic absorption spectrometer, inductively coupled plasma mass spectrometer, $\alpha$ and $\beta$ radioactivity measurement spectrometer and $\gamma$ radioactivity detectors. The related reference materials are all standard reagents associated with the automated systems and consensus standards (whole-body or pulmonary phantoms) used for gamma radioactivity measurements. Category 3 concerns testing equipment which does not provide results but the incorrect operation of which may affect the result or be the cause of a noncompliant result. Among this equipment, the MBL differentiates equipment to which metrological equipment is associated: refrigerators, freezers, centrifuges, ovens, incubators, thermostatic bath stirrers, dialyzers and data transfer IT equipment.

All this equipment (apart from IT equipment which is listed in another document) is recorded in an "equipment list" document (Fig. 2). The equipment is defined by category (1, 2 or 3$)$, type, make and reference, serial number, number and location, field of use (biology, toxicology, radiotoxicology), the criticality of the device and its metrological link.

\section{Document control}

Both the GBEA and standard NF EN ISO 15189 require the MBL to draw up and control documents relating to metrology. On the one hand, these documents are organizational: in the MBL we have general procedures such as "Control of measuring and test equipment" and "Calibrating measuring and control devices". There are also instructions "Drawing up and managing control cards" and 
"Checking and correct use of volumetric piston devices". Each instrument or automated system has its own operating procedure and there are specific operating procedures for the complex calibration of certain radiotoxicology instruments "Calibration and verification of whole-body anthroporadiometric equipment". On the other hand, there are the documents required to ensure metrological traceability: equipment list, method verification or validation files, maintenance logs, calibration certificates, monitoring cards, control cards, record sheets, reproducibility monitoring, precision, temperature recordings, etc. We will illustrate the resources and methods implemented in our MBL to control the instruments belonging to each category described above. The process is described in the procedure "Control of measuring and test equipment" in the form of a very general logic diagram (Fig. 3).

\section{Metrological control of measuring instruments}

This chapter will cover the resources and methods implemented for the metrological control of measuring instruments in the previously described category 1: scales, weights, thermometers, hygrometers, pipettes, chronometers and standard radioactive sources.

\subsection{Calibrations}

This equipment is calibrated externally or on site (scales) by "Calibration" service providers accredited either by Cofrac or by a foreign accreditation organization recognized by Cofrac when calibration is carried out outside France.

The frequency of calibrations and verifications is determined by the metrology manager: twice a year for scales, once a year for pipettes, thermometer and hygrometers, once every two years for weights.

The chronometers (countdown timers) have been calibrated once, when they were received in the MBL. The standard radioactive sources were calibrated by the manufacturer. There are no additional external calibrations: the regulatory difficulties in managing radioactive sources and transporting radioactive materials have resulted in the MBL only carrying out verifications.

An example of a record sheet for a category-1 measuring instrument is shown in Figure 4.

The working thermometers and hygrometers are connected internally by the metrology manager with the same frequency as the external calibrations [12]. A spreadsheet is used to obtain the average measurement deviation and uncertainty $U_{\text {connection }}(k=2)$. A "Temperature recorder connection" recording is taken and printed by the metrology manager (Fig. 5). The uncertainty calculation takes into account the uncertainty of the standard thermometer, reliability uncertainty and the thermometer resolution uncertainty.

We have not included the chamber homogeneity uncertainty as we considered it to be negligible: during connection, the two temperature recorders are side by side.

\subsection{Calibration verification}

The verification programme was drawn up by the metrology manager. On the one hand there are checks carried out by external organizations who perform calibrations: pipettes (annual frequency), scales (half-yearly frequency) and standard thermometer (annual frequency). The countdown timers are checked by the metrology manager (half-yearly frequency).

On the other hand, there are simplified daily checks carried out by the different MBL technicians: pipettes, scales.

The radioactive source verification follows a different programme. The sealed sources used for measuring alpha or gamma radioactivity are not checked directly. It is the combined use of different standards for the same detector or the same standard on different detectors which validate the verification.

Liquid radioactive sources are verified in comparison with radiological activity, volume to volume, between the standard source to verify and a reference solution of a referenced activity. This reference solution is provided by Procorad, an organization which carries out intercomparisons. The found value associated with its measurement uncertainty must cover the assigned value associated with its calibration certificate uncertainty.

\section{Metrological control of analysis equipment: automated biology and toxicology analysis systems}

Biology and toxicology analysis equipment may be complex systems: sampling and distribution system, thermostatisation system, measuring system (spectrophotometers, flow cytometer, mass spectrometer, etc.). The different elements must be checked and calibrated whenever possible by the user or the equipment supplier's aftersales department.

Temperature verification using a standard thermal probe may prove difficult when the thermostatic compartment is difficult to access. The accuracy of the wavelengths used by the spectrophotometer must be checked. The use of thermosensitive solutions to check the thermostatic compartment or holmium salts for wavelengths [13] is inaccessible to the MBL. Furthermore, their control cannot be isolated from the rest of the analytical system which encompasses the instrument, the method, the reagents, the reference materials and the related IT system.

That is why the MBL uses equipment with the CE mark according to directive 98/79-CE relating to In Vivo Diagnosis medical devices [14], guaranteeing the satisfaction of a number of essential requirements: analytical performance (repeatability, reproducibility, precision, sensitivity and diagnostic specificity, detection limit, etc.), traceability of values attributed to calibration or control equipment, reference intervals and management of internal quality controls. 


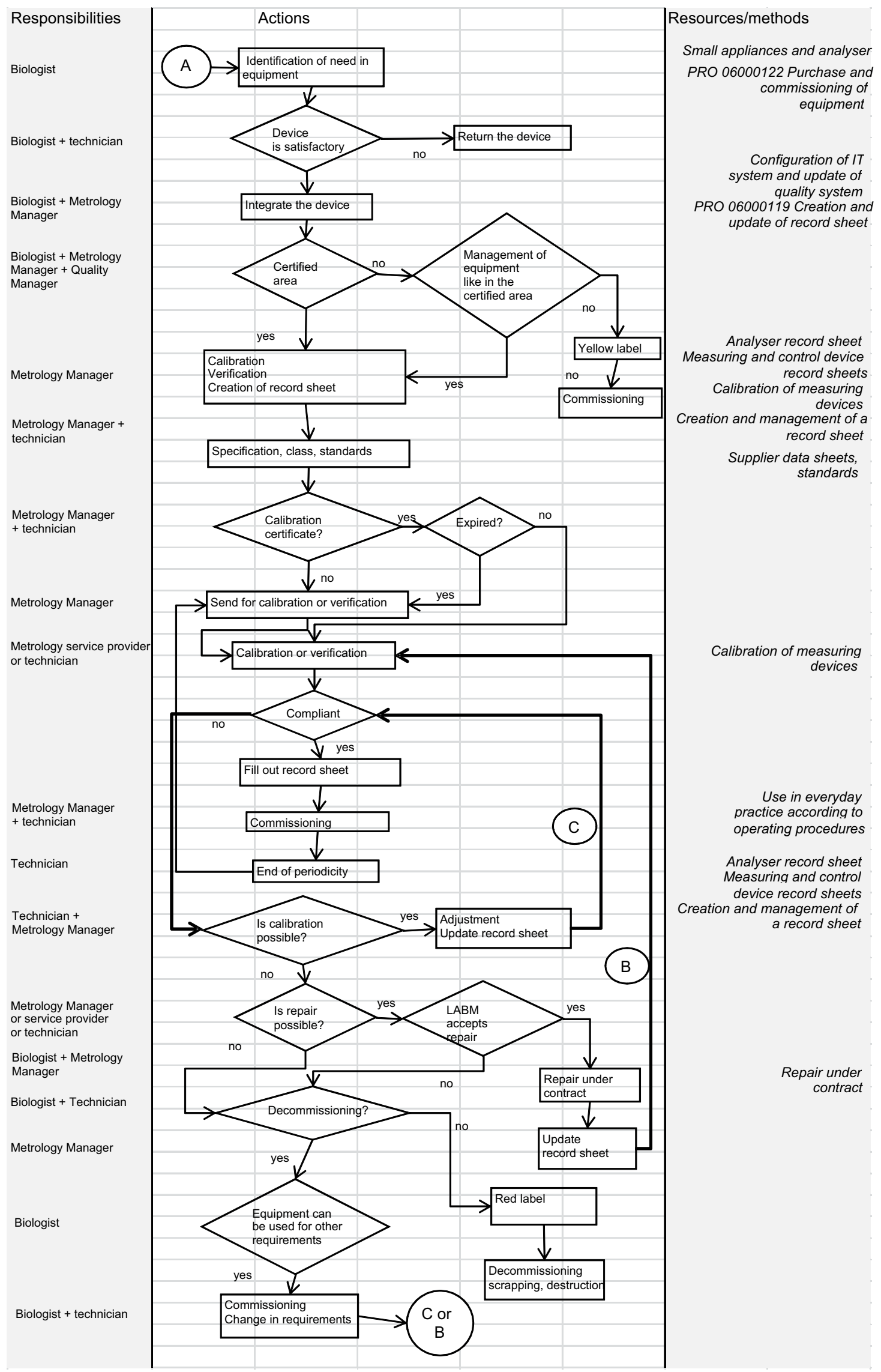

Fig. 3. Control of measuring and test equipment. 


\begin{tabular}{|c|c|c|c|c|c|c|c|}
\hline \multicolumn{8}{|c|}{ S0801 RQN ENR 06000116 B Measuring and control device record sheet } \\
\hline \multicolumn{8}{|c|}{ Implementation date: $17 / 02 / 2012$} \\
\hline NAME MAKE & \multicolumn{2}{|c|}{ MAKE/MODEL } & \multicolumn{2}{|c|}{ SERIAL INC } & LOCATION & \multicolumn{2}{|c|}{ Reference document } \\
\hline \multirow{2}{*}{ Pipette Type A } & \multirow{2}{*}{\multicolumn{2}{|c|}{ Biohit $0.1-25 \mathrm{ml}$}} & \multirow{2}{*}{\multicolumn{2}{|c|}{5066554}} & \multirow{2}{*}{ Module 122} & \multicolumn{2}{|c|}{ NF EN ISO/CEI 17025} \\
\hline & & & & & & NF EN I & 015189 \\
\hline \multicolumn{4}{|c|}{ Calibration procedure } & & \multicolumn{3}{|c|}{ SYM S0801 RQN PRO 06000118} \\
\hline \multicolumn{4}{|c|}{ External calibration periodicity } & \multirow{2}{*}{\multicolumn{4}{|c|}{1 year }} \\
\hline \multicolumn{4}{|c|}{ External verification periodicity } & & & & \\
\hline \multicolumn{8}{|c|}{ New device in accordance with specifications, arrived on $12 / 06 / 2006$} \\
\hline \multicolumn{7}{|c|}{ COM: Commissioning CAL:Calibration V:Verification CON:Connection M: Maintenance } & \\
\hline com & CAL & $\mathbf{v}$ & CON & M & Comment & Party invo & $\begin{array}{l}\text { Initials } \\
\text { ed(metrologica } \\
\text { confirmation) }\end{array}$ \\
\hline $07 / 06 / 2006$ & $\mathbf{X}$ & & & & COFRAC certification no. 5968CE05 & Biohit & $\mathrm{SP}$ \\
\hline $07 / 06 / 2006$ & & $\mathrm{X}$ & & & VC no. 5968CV05 compliant & Biohit & $\mathrm{SP}$ \\
\hline $12 / 06 / 2006 \mathrm{X}$ & & & & & & MJP & $\mathrm{SP}$ \\
\hline $04 / 01 / 2007$ & & $\mathbf{X}$ & & & VC no. 8V07/VBP2 compliant & Biohit & $\mathrm{SP}$ \\
\hline $08 / 06 / 2007$ & $\mathbf{x}$ & $\mathbf{X}$ & & $\mathbf{X}$ & COFRAC no. 6189 compliant & Biohit & $\mathrm{SP}$ \\
\hline $30 / 10 / 2007$ & & $\mathbf{X}$ & & & VC 81886V07/VBP3 compliant & Biohit & SP \\
\hline $13 / 02 / 2008$ & $\mathbf{X}$ & $\mathbf{X}$ & & $\mathbf{x}$ & CC no. 5455CE08 + VC compliant & Biohit & $\mathrm{SP}$ \\
\hline $29 / 07 / 2008$ & & $\mathbf{X}$ & & & VC 1914V08/VBP2 compliant & Biohit & SP \\
\hline $10 / 02 / 2009$ & $\mathbf{x}$ & $\mathbf{x}$ & & $\mathbf{x}$ & CC no. 5289CE09 + VC compliant & Biohit & $\mathrm{SP}$ \\
\hline May-09 & & & & & $\begin{array}{l}\text { New verification pace } \\
\text { Improvement action no. 53) }\end{array}$ & SP & SP \\
\hline $18 / 09 / 2009$ & & $\mathbf{x}$ & & & $\begin{array}{l}\text { Internal verification of rep. on } 10 \text { weighing a } \\
\text { and precision on } 10 \text { weighting actions, } \\
\text { Excel spreadsheet attached }\end{array}$ & $\begin{array}{l}\text { ctions } \\
\text { SP }\end{array}$ & SP \\
\hline $15 / 02 / 2010$ & & $\bar{X}$ & & & VC 157V10/VBP3 compliant & Biohit & $\mathrm{SP}$ \\
\hline $01 / 03 / 2010$ & $\mathbf{X}$ & & & $\mathbf{X}$ & CC no. 5460CE10 & Biohit & $\mathrm{SP}$ \\
\hline $21 / 01 / 2011$ & & $\mathbf{X}$ & & & VC 125V11/VBP3 compliant & Biohit & SP \\
\hline $31 / 01 / 2011$ & $\mathbf{x}$ & & & $\mathbf{X}$ & CC no. 5331CE11 & Biohit & $\mathrm{SP}$ \\
\hline $17 / 05 / 2011$ & & & & & $\begin{array}{l}\text { Out of order Sent for repair and } \\
\text { calibration }\end{array}$ & SP & SP \\
\hline $15 / 06 / 2011$ & $\mathbf{X}$ & & & & CC no. 7415CE11 + CD compliant & Biohit & $\mathrm{SP}$ \\
\hline $17 / 01 / 2012$ & & $\mathbf{x}$ & & & VC 125V11/VBP3 compliant & Biohit & $\mathrm{SP}$ \\
\hline $09 / 02 / 2012$ & $\mathbf{X}$ & & & $\mathbf{X}$ & CC no. 10511CE12 & Biohit & $\mathrm{SP}$ \\
\hline $10 / 01 / 2013$ & & & & & $\begin{array}{l}\text { Sent for verification, maintenance \& } \\
\text { calibration }\end{array}$ & SP & SP \\
\hline $21 / 01 / 2013$ & & $\mathbf{x}$ & & $\mathbf{x}$ & $\begin{array}{l}\text { VC no. 35V13/VBD3 compliant for } 25 \mathrm{ml} \\
\text { nozzle }\end{array}$ & Biohit & SP \\
\hline $08 / 03 / 2013$ & $\mathbf{X}$ & & & & CC no. 11175 CE13 + CD compliant $(25 \mathrm{ml})$ & Biohit & $\mathrm{SP}$ \\
\hline $08 / 03 / 2013$ & $\mathbf{X}$ & & & & CC no. 11176CE13 + CD compliant(10ml) & Biohit & SP \\
\hline $20 / 03 / 2013$ & & & & & Instrument returned to lab & Biohit & SP \\
\hline $21 / 03 / 2013$ & & $\mathbf{X}$ & & & Verification of CC nos. on report and pipette & $\mathrm{SP}$ & SP \\
\hline
\end{tabular}

Fig. 4. Record sheet.

SYM S0801 RQN ENR 07000207 B Temperature recorder connection

Implementation date : 27/03/2013

\begin{tabular}{|c|c|c|c|c|c|}
\hline \multicolumn{2}{|c|}{ RECORDER IDENTIFICATION } & \multicolumn{3}{|c|}{ Testo $177-T 2 n^{\circ} 01174371 / 602$ Frigo 114} & \\
\hline DATE & & \multicolumn{3}{|c|}{$27 / 03 / 2013$} & \\
\hline STANDARD & & \multicolumn{3}{|c|}{ Tes to $177-T 2 n^{\circ} 01007415 / 409$} & \\
\hline \multicolumn{2}{|c|}{ CALIBRATION CERTIFCATE NO. } & \multicolumn{3}{|c|}{ T44216 D-K-15070-01-01 2013-02 } & \\
\hline $\begin{array}{l}\text { Average*** } \\
\text { standard } \\
\text { values }\end{array}$ & $\begin{array}{l}\text { Average*** } \\
\text { Recorder } \\
\text { values }\end{array}$ & $\begin{array}{c}\text { Average } \\
\text { measurement } \\
\text { deviation }\end{array}$ & $\begin{array}{c}\text { Measurement } \\
\text { uncertainty } \\
U_{\text {reliability }}{ }^{*}\end{array}$ & $\begin{array}{c}\text { Measurement } \\
\text { uncertainty } \\
\mathrm{U}_{\text {standard }}\end{array}$ & $\begin{array}{c}\text { Measurement } \\
\text { uncertainty } \\
U_{\text {connection }}\end{array}$ \\
\hline${ }^{\circ} \mathrm{C}$ & ${ }^{\circ} \mathrm{C}$ & ${ }^{\circ} \mathrm{C}$ & ${ }^{\circ} \mathrm{C}$ & ${ }^{\circ} \mathrm{C}$ & ${ }^{\circ} \mathrm{C}$ \\
\hline 5.22 & 5.17 & -0.05 & 0.12 & 0.34 & 0.4 \\
\hline * & \multicolumn{5}{|c|}{ Measurement uncertainty of the $\mathrm{m}$ easuring device during calibration. } \\
\hline ** & \multicolumn{5}{|c|}{ Measurement uncertainty provided by the calibration certificate } \\
\hline *** & \multicolumn{4}{|c|}{ Average of 10 measurements at rate } & \\
\hline \multirow{2}{*}{\multicolumn{2}{|c|}{ Metrological confirmation: }} & \multicolumn{4}{|c|}{ Compliant according to the laboratory's requirements } \\
\hline & & \multicolumn{3}{|c|}{ INITIALS: } & \\
\hline
\end{tabular}

Fig. 5. Temperature recorder connection sheet. 


\begin{tabular}{|c|c|c|c|c|c|c|c|c|}
\hline \multirow{2}{*}{\multicolumn{7}{|c|}{$\begin{array}{l}\text { SH FORM 43 REPEATABILITY } \\
\text { Outsourced IQC serum (AD } 3738 \text { and 39 Probioqual) }\end{array}$}} & \multirow{2}{*}{\multicolumn{2}{|c|}{ Target }} \\
\hline & & & & & & & & \\
\hline Measurand & Unit & Level & $\begin{array}{l}\text { Mean } \\
(\mathrm{n}=30 \text { not inc. } \\
\text { aberrant) }\end{array}$ & \multirow{2}{*}{$\begin{array}{l}\text { CVR (\%) } \\
\text { LAM DIF } \\
1.5\end{array}$} & \multirow{2}{*}{$\begin{array}{c}\begin{array}{c}\text { CVR (\%) } \\
\text { Supplier }\end{array} \\
2.0\end{array}$} & $\begin{array}{l}\text { CVR }(\%) \\
\text { SFBC }\end{array}$ & Supplier & SFBC \\
\hline & \multirow{3}{*}{$\mathrm{mg} / \mathrm{l}$} & Low & 33.5 & & & 2.7 & C & C \\
\hline \multirow{2}{*}{ Uric acid } & & Medium & 50.1 & 0.6 & 2.0 & 2.4 & C & C \\
\hline & & Haut & 85.7 & 0.7 & 2.0 & 2.1 & c & $\mathrm{C}$ \\
\hline \multirow{3}{*}{ ALAT } & \multirow{3}{*}{ UI/L } & Low & 28.1 & 2.0 & 2.0 & 4.5 & C & C \\
\hline & & Medium & 63.7 & 0.9 & 2.0 & 4.5 & $\mathrm{C}$ & C \\
\hline & & High & 199.8 & 0.3 & 2.0 & 3.8 & $\mathrm{C}$ & $\mathrm{C}$ \\
\hline \multirow{3}{*}{ AMYLASE } & \multirow{3}{*}{ UI/L } & Low & 75.0 & 0.9 & 2.0 & 4.5 & $\mathrm{C}$ & C \\
\hline & & Medium & 152.5 & 0.5 & 2.0 & 4.5 & C & C \\
\hline & & High & 310.9 & 0.5 & 2.0 & 3.8 & $c$ & $c$ \\
\hline \multirow{3}{*}{ ASAT } & \multirow{3}{*}{ UI/L } & Low & 34.1 & 1.9 & 2.0 & 4.5 & $\mathrm{C}$ & $\mathrm{C}$ \\
\hline & & Medium & 61.7 & 1.1 & 2.0 & 4.5 & $\mathrm{C}$ & $\mathrm{C}$ \\
\hline & & High & 197.9 & 0.4 & 2.0 & 3.8 & $\mathrm{C}$ & $\mathrm{C}$ \\
\hline \multirow{3}{*}{ Total bilirubin } & \multirow{3}{*}{$\mathrm{mg} / \mathrm{l}$} & Low & 11.2 & 1.8 & 2.0 & 5.1 & C & C \\
\hline & & Medium & 22.2 & 1.6 & 20 & 4.2 & C & c \\
\hline & & High & 30.5 & 1.1 & 2.0 & 3.2 & C & C \\
\hline \multirow{3}{*}{ Chloride } & \multirow{3}{*}{$\mathrm{mmol} / \mathrm{L}$} & Low & 81.2 & 0.3 & 1.0 & 1.2 & C & C \\
\hline & & Medium & $\begin{array}{l}01.2 \\
104.1\end{array}$ & 0.5 & $\frac{1.0}{1.0}$ & $\frac{1.2}{1.2}$ & C & C \\
\hline & & High & 111.8 & 0.4 & 1.0 & 1.2 & $c$ & $c$ \\
\hline \multirow{3}{*}{ Total cholesterol } & \multirow{3}{*}{ g/L } & Low & 1.2 & 0.6 & 2.0 & 3.0 & $\mathrm{C}$ & $\mathrm{C}$ \\
\hline & & Medium & $\frac{1.2}{2.0}$ & 0.0 & 2.0 & 3.0 & C & C \\
\hline & & High & 2.8 & 0.7 & 2.0 & 3.0 & $c$ & $c$ \\
\hline \multirow{3}{*}{ HbA1c } & \multirow{3}{*}{$\%$} & Low & 5.1 & 0.6 & 4.0 & 3.2 & C & C \\
\hline & & Medium & & & 4.0 & 2.9 & & \\
\hline & & High & 9.9 & 0.8 & 4.0 & 2.6 & $C$ & $c$ \\
\hline \multirow{3}{*}{ CRP } & \multirow{3}{*}{$\mathrm{mg} / \mathrm{l}$} & Low & 6.58 & $\frac{0.0}{1.4}$ & 4.0 & 9.0 & $\mathrm{C}$ & $\mathrm{C}$ \\
\hline & & Medium & & & 4.0 & 4.5 & C & c \\
\hline & & High & 36.09 & 1.0 & 4.0 & 3.8 & C & C \\
\hline
\end{tabular}

Fig. 6. Repeatability.

In this context, the method and means implemented for the metrological confirmation of this measuring equipment belonging to category 2 as defined previously are fundamentally different from those in category 1 .

The MBL has defined three main steps for setting up and using this analysis equipment:

- The choice of measuring instrument, ensuring that the methods used have been validated using independent publications and that analytical performance and metrological traceability comply with clinical requirements and current best practice.

- The installation of the measuring instrument with the drawing up of the verification file according to the recommendations of Cofrac document SH GTA 04 [15]. This step allows metrological confirmation of the performance listed according to standard NF EN ISO $10012^{(4)}$ and complies with Chapter 5.3.2 of standard NF EN ISO 15189 [3] "It must be demonstrated (during installation and current use) that the equipment is able to achieve the required performance and complies with the specifications relating to the analyses concerned".

- The monitoring of metrological confirmation throughout the use period. These periodic confirmations are organized at regular intervals appropriately defined according to the equipment and parameters measured.

We will not develop the first step as, although essential, it is dependent upon the information available when the equipment is being chosen.

\subsection{Verifications-validation during installation}

The MBL applied Cofrac document SH GTA 04 [15]. The verification is carried out on bibliographical bases and onsite measurements. Only analytical specificity, reagent stability after opening, robustness and comparison with a reference method have been the subject of a bibliography without verification in our MBL. Intermediate reliability (repeatability, reproducibility), measurement precision for certain parameters, interference, reference intervals (or normal or usual values) and the comparison with the method already used in the MBL were the subject of a bibliography and a verification.

During installation, the supplier carries out a number of tests allowing its validation for operation by the MBL, particularly to check that the transport has not damaged the performance identified in the factory. However, these tests do not cover all the parameters to be checked and the performance criteria are not necessarily those of our MBL.

The biologist defines a test schedule to carry out the different metrological confirmation measurements with the goal being to cover as fully as possible the study of pathologies which may be encountered and to maximise the use of substrates the closest to the matrices usually encountered (blood, urine).

We work on pool of serum or urine, whole blood of a healthy volunteer, internal control reagents from the manufacturer or other supplier and external quality evaluation reagents.

Intermediate reliability, precision and uncertainties are compared with the performance published by the supplier and in reference publications or with current best practice [9-11]. Figures 6-8 show examples of performance verifications for an automated immunology and haematology biochemistry system as described in Cofrac document SH GTA 14 [16]: "the result of the uncertainty itself is not evaluated in relation to a compliance criterion and can therefore not be compared with indicators from literature such as Ricos Valtec. The uncertainty assessment is not a selection criterion for the method". We have chosen to compare uncertainties for metrological monitoring and confirmation and the improvement process. The MBL on 


\begin{tabular}{|c|c|c|c|c|c|c|c|c|c|c|c|c|c|c|}
\hline \multicolumn{15}{|c|}{ SH FORM 43 REPRODUCIBILITY } \\
\hline & & & & & & & & & & & Targ & & & \\
\hline \multirow[b]{2}{*}{ Measurand } & \multirow[b]{2}{*}{ Unit } & \multirow[b]{2}{*}{ Level } & \multirow[b]{2}{*}{ Mean } & \multirow[b]{2}{*}{$\begin{array}{l}\text { CVR (\%) } \\
\text { LAM DIF }\end{array}$} & \multirow{2}{*}{$\begin{array}{l}\text { CVR (\%) } \\
\text { Supplier } \\
\text { summary }\end{array}$} & \multirow[b]{2}{*}{$\begin{array}{c}\text { CVR (\%) } \\
\text { SFBC }\end{array}$} & \multicolumn{3}{|c|}{ Ricos (I) } & \multirow[t]{2}{*}{ Supplier } & \multirow[t]{2}{*}{ SFBC } & \multicolumn{3}{|c|}{ RICOS } \\
\hline & & & & & & & Min & Med & Opt & & & Min & Med & Opt \\
\hline \multirow{3}{*}{ Total PSA } & \multirow{3}{*}{$\mu \mathrm{g} / \mathrm{l}$} & Low & 0.49 & 4.9 & 8.0 & 20.0 & 13.7 & 9.1 & 4.6 & $\mathrm{C}$ & $\bar{C}$ & $\bar{C}$ & $\bar{C}$ & NC \\
\hline & & Medium & 3.79 & 4.4 & 8.0 & 7.0 & 13.7 & 9.1 & 4.6 & $\mathbf{C}$ & $\mathrm{C}$ & $\mathrm{C}$ & C & $\mathbf{C}$ \\
\hline & & High & 24.44 & 3.9 & 8.0 & 7.0 & 13.7 & 9.1 & 4.6 & C & C & C & C & C \\
\hline \multirow{3}{*}{ Free PSA } & \multirow{3}{*}{$\mu \mathrm{g} / \mathrm{l}$} & Low & 0.41 & 2.3 & 8.0 & 20.0 & 13.7 & 9.1 & 4.6 & $\bar{C}$ & $\bar{C}$ & $\bar{C}$ & (C) & $\bar{C}$ \\
\hline & & Medium & 1.04 & 2.5 & 8.0 & 7.0 & 13.7 & 9.1 & 4.6 & $\mathrm{C}$ & $\mathbf{C}$ & $\mathrm{C}$ & $\mathrm{C}$ & C \\
\hline & & High & 7.29 & 2.6 & 8.0 & 7.0 & 13.7 & 9.1 & 4.6 & $\mathrm{C}$ & $\mathrm{C}$ & C & C & $C$ \\
\hline \multirow{3}{*}{ Ferritin } & \multirow{3}{*}{$\mu \mathrm{g} / \mathrm{l}$} & Low & 20.56 & 4.9 & 9.0 & 10.0 & 14.6 & 9.7 & 4.9 & $\bar{C}$ & $\bar{C}$ & $\bar{C}$ & $\bar{C}$ & NC \\
\hline & & Medium & 143.86 & 3.8 & 9.0 & 8.0 & 14.6 & 9.7 & 4.9 & $\mathrm{C}$ & $\mathrm{C}$ & $\mathrm{C}$ & $\mathrm{C}$ & $\mathrm{C}$ \\
\hline & & High & 369.40 & 5.0 & 9.0 & 8.0 & 14.6 & 9.7 & 4.9 & C & C & C & C & NC \\
\hline \multirow{3}{*}{ TSH } & \multirow{3}{*}{$\mathrm{UI} / \mathrm{L}$} & Low & 0.10 & 4.2 & 10.0 & 20.0 & 10.7 & 7.1 & 3.6 & $\mathrm{C}$ & $\bar{C}$ & $\mathrm{C}$ & $\bar{C}$ & $\mathrm{NC}$ \\
\hline & & Medium & 5.82 & 3.5 & 10.0 & 7.0 & 10.7 & 7.1 & 3.6 & $\mathrm{C}$ & $\mathrm{C}$ & $\mathrm{C}$ & $\mathrm{C}$ & $\mathrm{C}$ \\
\hline & & High & 30.19 & 3.7 & 10.0 & 5.0 & 10.7 & 7.1 & 3.6 & $C$ & C & $C$ & C & $\mathrm{NC}$ \\
\hline \multirow{3}{*}{ Anti-HBs Ab } & \multirow{3}{*}{ UIII } & Low & & & & & 0.0 & & 0.0 & & & & & \\
\hline & & Medium & 15.33 & 7.8 & 9.4 & & 0.0 & 0.0 & 0.0 & C & & NC & $\mathrm{NC}$ & $\mathrm{NC}$ \\
\hline & & High & 86.23 & 7.7 & 8.9 & & 0.0 & 0.0 & 0.0 & $\mathrm{C}$ & & $\mathrm{NC}$ & $\mathrm{NC}$ & $\mathrm{NC}$ \\
\hline
\end{tabular}

Fig. 7. Reproducibility.

the other hand is obliged to compare the industrial toxicology measurement uncertainty for blood lead levels assay as the uncertainty value is set by the regulations $[5,7,17]$.

The verification file follows the layout of Cofrac form SH FORM 43 [17]. This document includes the performance parameters described above and adds a chapter on the description and implementation of the method and risk control.

\subsection{Metrological control and monitoring of equipment}

The declaration of compliance starts to be monitored once the verification file has been signed by the lead biologist.

Metrological confirmation control and monitoring are carried out on a daily basis. Calibration is carried out at variable frequencies according to the measuring equipment. Calibration may be carried out each time the equipment is used, like in toxicology (metal measurement) using the atomic absorption spectrometer or the inductively coupled plasma mass spectrometer, or in biochemistry with blood potassium or sodium measurement. Calibration may be carried out each time the reagent lot or standard (biochemistry) is changed.

In haematology, calibration is carried out in the factory by the manufacturer. The MBL only carries out calibration readjustments with the help of the supplier's aftersales department.

Calibration is validated and monitored using internal quality control (IQC) and external quality assessment (EQA) with the MBL being registered in various intercomparison programmes in order to cover practically the whole analysis area carried out by the MBL: Probioqual (biochemistry, haematology), Centre Toulousain pour le Contrôle de qualité en biologie clinique (Toulouse centre for quality control in clinical biology) or CTCB (haematology, virology), the Centre de Toxicologie du Québec (Quebec toxicology centre) or CTQ (toxicology), AGLAE (toxicology and bacteriology), Procorad (radiotoxicology). The MBL follows the recommendations of the Cofrac document on quality control in medical biology [18] $\mathrm{SH}$ GTA 06.

\subsubsection{Internal quality control (ICQ)}

ICQ enables our laboratory to monitor the validity of measuring system performance and calibrations over time by calculating the reproducibility variation coefficient (CVR\%) of each analyte. Internal quality controls are included at the beginning and end of a series of measurements, making it possible to validate calibration (beginning of series) and the series of measurements (end of series).

The values obtained are compared with the control level target value determined during a preliminary verification period before introducing the lot of said control. Control values are monitored in material form on control cards used according to rules for identifying and anticipating random or systematic variations. The MBL chose to follow Westgard rules [19]. There are two levels of interpretation: rejection rules and warning rules. We selected the following rejection rules:

$1_{3 s}$ : One value more than three standard deviations from the mean.

$2_{2 s}$ : Two consecutive values more than two standard deviations from the same side of the mean.

$1_{4 s}$ or $\mathrm{R}_{4 s}$ : Two consecutive values more than four standard deviations apart.

We selected the following warning rules:

$1_{2 s}$ : One value more than two standard deviations from the mean.

$10_{x}$ : Ten consecutive values on the same side of the mean.

We set up three logic diagrams to determine the different actions according to the cases encountered: a logic diagram (Fig. 9) when a single control level is rejected, a logic diagram (Fig. 10) when several control levels are rejected and a logic diagram (Fig. 11) for the interpretation of controls carried out at the end of the series.

These logic diagrams are easy to apply for analyses measured on a daily basis and which can be easily and rapidly calibrated before measures are launched by the automated system. 


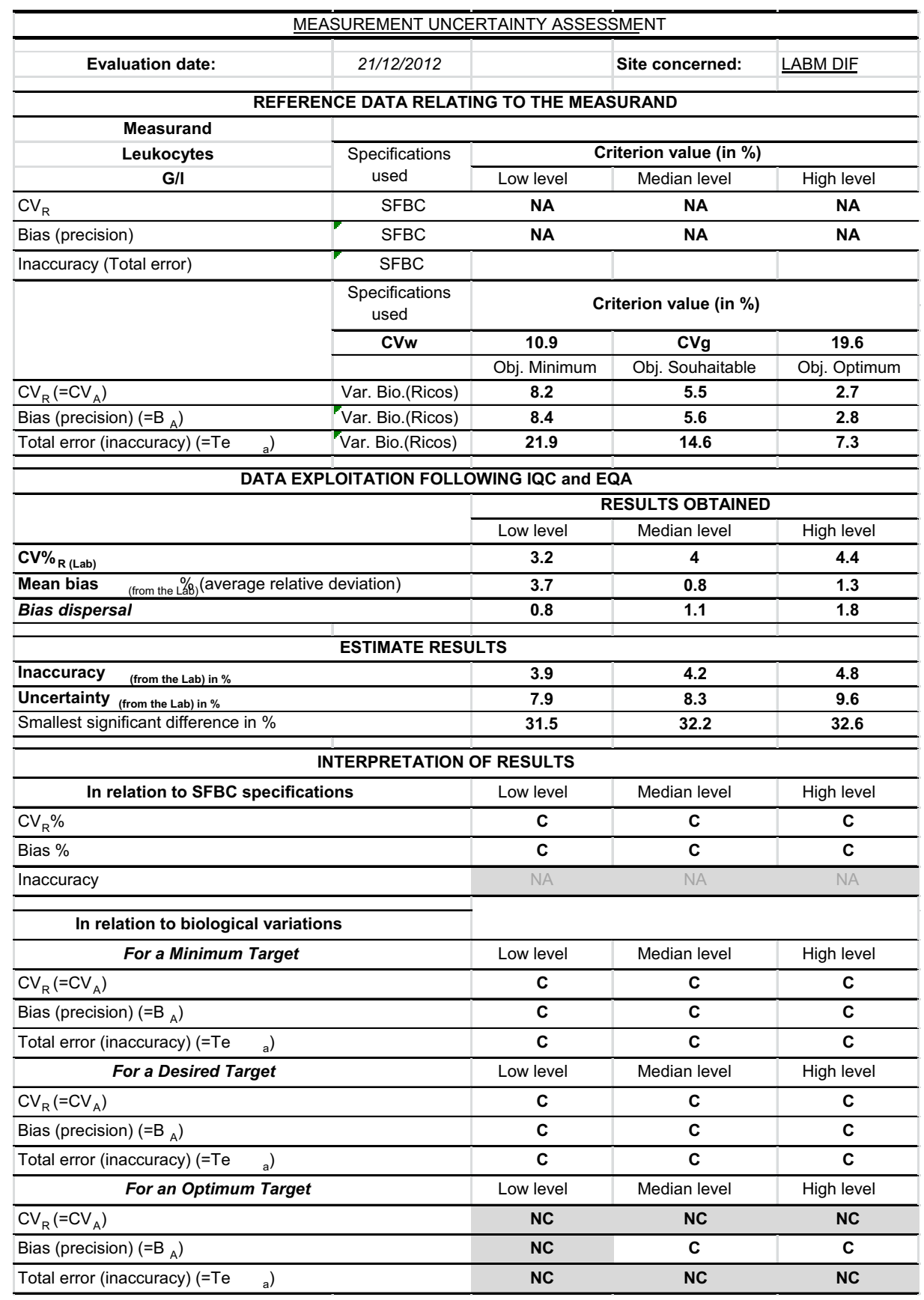

Fig. 8. Measurement uncertainty assessment.

A monthly summary of $\mathrm{CVR} \%$ is produced to check that the values correspond to those given by the supplier or literature.

\subsubsection{External quality assessment (EQA)}

Our MBL participates in several intercomparison exercises to carry out the External Quality Assessment (EQA). In biology and toxicology, the MBL participates in four different exercises outside the mandatory EQAs organized by the Agence Nationale de Sécurité du Médicament et des produits de Santé (ANSM) (French agency of medicine and health products safety): Probioqual, CTCB, CTQ and AGLAE mentioned above.

These EQAs evaluate accuracy for the different measurands, whether they are quantitative or qualitative analyses. The MBL monitors the relative bias of the measurement result in relation to the robust mean provided by the users of the same automated system and according to the same technique. If the number of users is considered to be insufficient by the intercomparison organization, we compare our results in relation to all users. The accuracy bias [20] is compared with those provided in references [9-11]. 


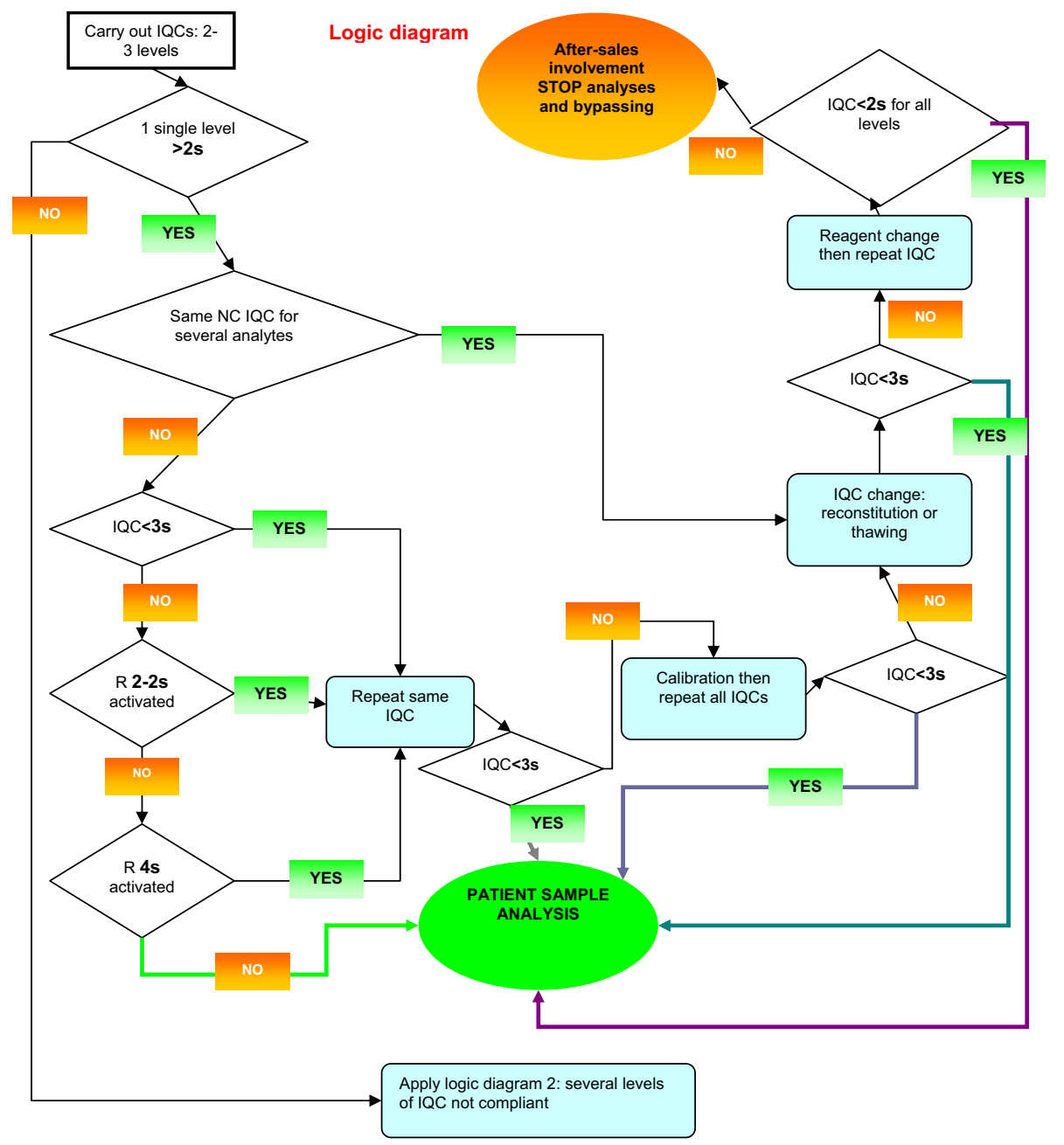

Fig. 9. Logic diagram 1.

The average value of the bias and the standard deviation are also calculated so they can be included in the uncertainty calculation of each measurand.

The MBL also monitors the Z-score for each measurement. The $Z$-score represents the standardized measurement of the laboratory bias calculated from the assigned value and the standard deviation for the aptitude assessment [21].

$$
Z \text {-score }=\left(\frac{X_{\text {lab }}-m_{\text {comparison group }}}{E T_{\text {comparison group }}}\right) .
$$

If the $Z$-score absolute value is lower than 2, the MBL's performance in relation to the comparison group is satisfactory. Between 2 and 3, the performance is debatable and a monitoring action is undertaken. If the $Z$-score is equal to or higher than 3 , the performance is considered as unsatisfactory and generates a corrective action, weighted by the accuracy bias value.

EQA monitoring is illustrated in Figure 12 for a biochemistry parameter and can be extrapolated to other MBL measurands (Fig. 12). The accuracy assessment is all the more relevant when the number of participants included in the calculation of the target value is statistically significant (higher than 30 if possible). It is a selection criterion for the intercomparison exercise, combined with ISO 9001 certification or accreditation according to ISO standard 17043 [20].

\subsection{Estimation of uncertainty}

The MBL endeavours to assess the measurement uncertainty of the results of quantitative methods, taking into account components influencing the analytical phase but also the components of the pre-analytical and postanalytical phases.

The difficulty is quantifying the influence of preanalytical and post-analytical phases. How can the influence of sampling time, choice of anticoagulant, sampler, etc. be quantified? The MBL analysed the different preanalytical and post-analytical influence factors. For each factor, the MBL studied the implementation of control actions to limit the influence of these factors. This approach was also implemented for the analytical phase and the MBL determined whether the IQC and/or EQA could quantitatively estimate the influence of each factor. 


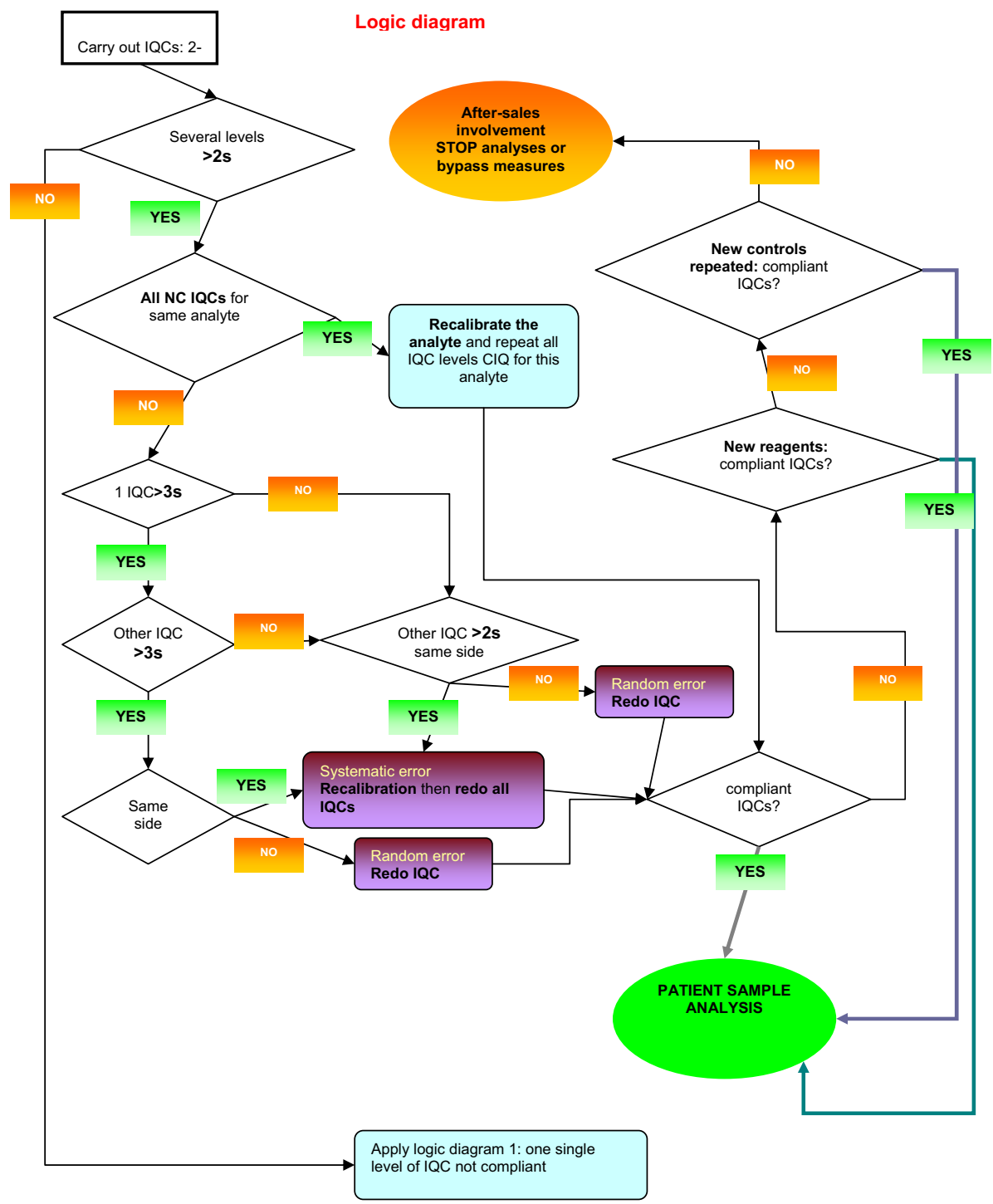

Fig. 10. Logic diagram 2.

Only biological variability is not taken into consideration.

The last step is to calculate uncertainty for different levels according to the formula published in Cofrac document SH GTA 14 [16], described in the "IQC/EQA" method (Chap 8.3 of SH GTA 14).

$$
u(c)=\sqrt{\left(\frac{C V R \times m}{100}\right)^{2}+\left(\frac{\bar{E}}{\sqrt{3}}\right)^{2}+\hat{\sigma}_{E}^{2}}
$$

where $C=$ concentration of analyte in the patient sample and $u(c)$ its uncertainty

$$
\begin{aligned}
\mathrm{CVR} & =\text { Reproducibility variation coefficient } \\
m & =\text { measurand value } \\
\bar{E} & =\text { mean deviation } E=\frac{\sum_{i}\left(x_{\text {lab }}-x_{\text {réf }}\right)}{n}:
\end{aligned}
$$

$\hat{\sigma}_{E}=$ standard deviation of deviations between the laboratory results and the assigned value

$$
\hat{\sigma}_{E}=\sqrt{\frac{\Sigma\left(E_{i}-E\right)^{2}}{n-1}} .
$$

This calculation is illustrated in Figure 8.

Standard NF EN ISO 15189 requires that the laboratory estimate measurement uncertainty. However, this calculation is not performed on a daily basis in practice as, with a few rare exceptions, the doctors receiving the results do not yet use them to make their diagnosis.

The MBL calculates the uncertainty on the blood lead levels result and informs the doctor as this is a regulatory obligation [7]. The MBL calculates the uncertainty on the result so it can produce interpretations in situations in which they are based on thresholds. We can illustrate this with the haemoglobin A1c assay when monitoring diabetics. 


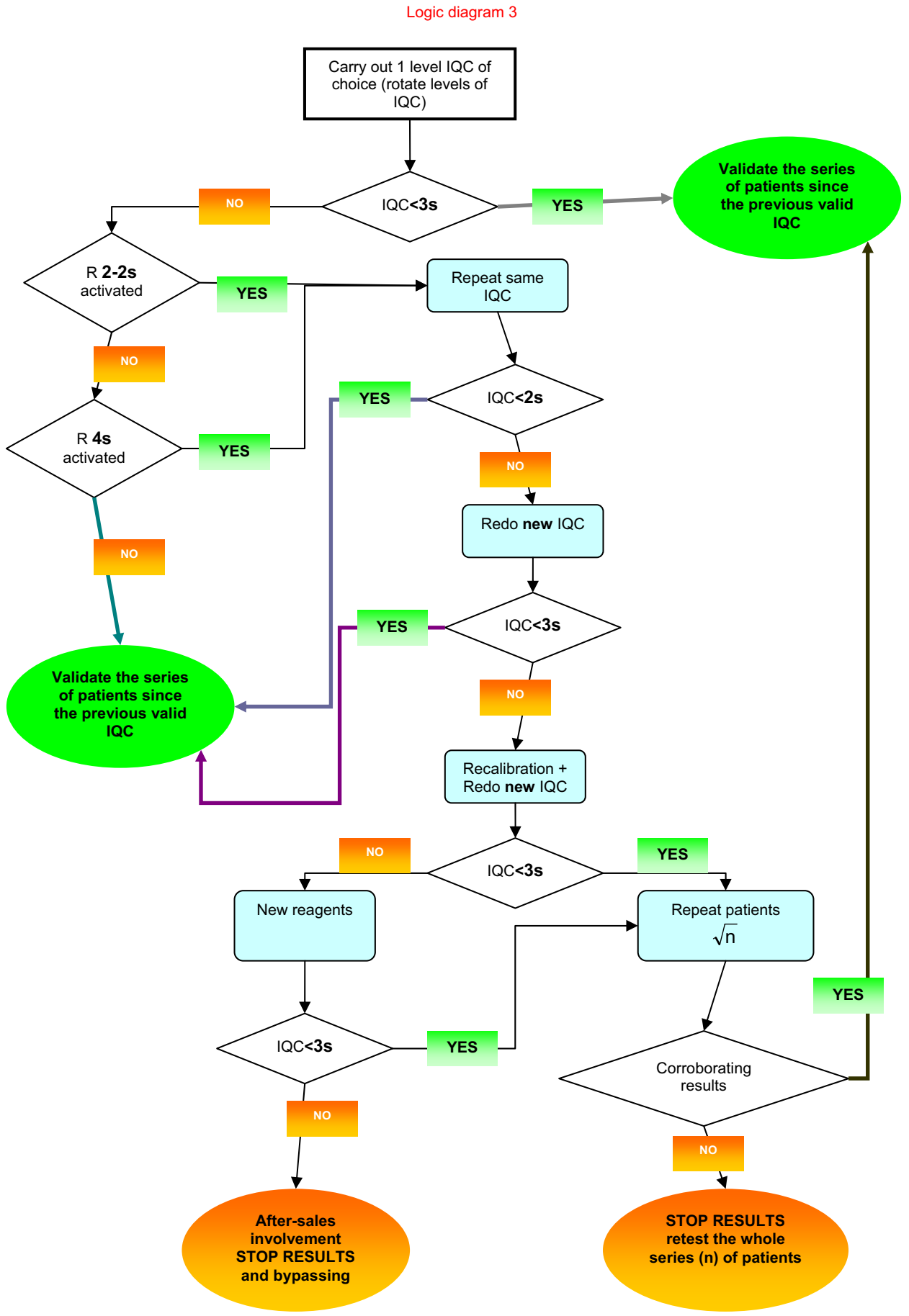

Fig. 11. Logic diagram 3.

The threshold which indicates that a treatment is correctly monitored and effective depends on the type of diabetes and treatment. The Haute Autorité de Santé in France (French national authority for health) gives a haemoglobin A1c threshold of $6.5 \%$ which must not be exceeded in the treatment of type-II diabetes. If the haemoglobin A1c assay result associated with its uncertainty is lower (or higher) than $6.5 \%$, the interpretation provided to the doctor is as follows: "Value of results statistically lower (or higher) than the threshold value". On the other hand, if the haemoglobin A1c assay result associated with its uncertainty covers the threshold value, whatever the value of the result (lower or higher than the threshold value of $6.5 \%$ ), the interpretation provided to the doctor is as follows: "Result to be considered as not different from the threshold value".

Using this example, we can demonstrate the benefit of well-controlled metrological confirmation. It can be a 


\begin{tabular}{|c|c|c|c|c|c|c|c|c|c|c|c|c|c|c|}
\hline \multicolumn{3}{|c|}{ Name of EQA } & \multicolumn{6}{|c|}{ PBQ Integra 400} & & & & & & \\
\hline \multicolumn{3}{|c|}{ PARAMETER TESTED: } & \multicolumn{6}{|c|}{ Blood creatinine } & Unit & \multicolumn{2}{|l|}{$\mu \mathrm{mol} / \mathrm{l}$} & & & \\
\hline Lot & $\begin{array}{c}\text { LABM } \\
\text { value } \\
X_{\text {lab }} \\
\end{array}$ & $\begin{array}{c}\text { General } \\
\text { value } \\
\mathbf{X}_{\text {refgen }} \\
\end{array}$ & $\mathbf{n}_{\text {Gen }}$ & CV\% & $\begin{array}{c}\text { z-score } \\
\text { Gen }\end{array}$ & $\begin{array}{r}\text { Bias } \\
(\%)\end{array}$ & $\begin{array}{l}\text { Value } \\
\text { Pairs } \\
X_{\text {refpairs }} \\
\end{array}$ & $\mathbf{n}_{\text {pairs }}$ & CV\% & $\begin{array}{c}\text { z- } \\
\text { score } \\
\text { Pairs } \\
\end{array}$ & $\begin{array}{r}\text { Bias } \\
(\%)\end{array}$ & $\begin{array}{c}\text { Max. } \\
\text { bias Gen } \\
(\%) \\
\end{array}$ & $\begin{array}{c}\text { Max. } \\
\text { bias Pair } \\
(\%) \\
\end{array}$ & ఫ্త \\
\hline 13BA09 & 40 & 42.8 & 1207 & 17.4 & -0.4 & -6.5 & 39.7 & 12 & 6.6 & 0.1 & 0.8 & & & \\
\hline 13BA19 & 71 & 69.6 & 1199 & 8.4 & 0.2 & 2.0 & 69.7 & 13 & 3.9 & 0.5 & $\overline{1.9}$ & & & \\
\hline 13BF01 & 97 & 95.3 & 363 & 6.1 & $\overline{0.3}$ & 1.8 & 96.2 & 34 & 3 & 0.3 & $\overline{0.8}$ & -6.5 & -2.1 & B \\
\hline 13BA04 & 107 & 112.0 & 1212 & 9.3 & -0.5 & -4.5 & 109.3 & 13 & 2.7 & -0.8 & -2.1 & & & \\
\hline & & & & & & & & & & & & & & \\
\hline 13ВА33 & 112 & 112.8 & 1214 & 8.4 & -0.1 & -0.7 & 109.4 & 18 & 5.2 & 0.5 & 2.4 & & & \\
\hline 13BF03 & 133 & 137.4 & 367 & 4.3 & -0.7 & -3.2 & 139.5 & 40 & 3.4 & -1.4 & -4.7 & & & \\
\hline 13BA24 & 186 & 192.9 & 1221 & 4.0 & -0.9 & -3.6 & 185.4 & 15 & 2.4 & 0.1 & 0.3 & -3.6 & -4.7 & M \\
\hline 13BF02 & 195 & 193.4 & 362 & 4.8 & 0.2 & 0.8 & 196.9 & 34 & 3 & -0.3 & -1.0 & & & \\
\hline 13BA29 & 277 & 291.7 & 1210 & 6.3 & -0.8 & -5.0 & 282.7 & 17 & 3.2 & -0.6 & -2.0 & & & \\
\hline 13BA14 & 633 & 651.3 & 1221 & 7.3 & -0.4 & -2.8 & 626.9 & 12 & 1.5 & 0.6 & 1.0 & & & \\
\hline & & & & & & & & & & & & & & \\
\hline & & & & & & & & & & & & -5.0 & -2.0 & $E$ \\
\hline & & & & & & & & & & & & & & \\
\hline & & & & & & & & & & & & & & \\
\hline & & & & & & & & & & & & & & \\
\hline
\end{tabular}

Fig. 12.

valuable aid for the doctor and patient. It can prevent unnecessary treatment being carried out or correct treatment being modified.

\section{Metrological control of analysis equipment: specific case of in vivo radiotoxicological measurements}

In the scope of monitoring internal contamination risks of personnel exposed to ionising radiation, the MBL carries out in vivo radiotoxicological measurements: anthroporadiometric measurements. These measurements are carried out on the whole body and on the lungs to identify contamination by artificial radioactive elements: cesium-137, iodine-131, thallium-201, etc.

Metrological confirmation of anthroporadiometric measurements is complex due to the very nature of the matrix (whole body) and the measurands (potentially highly toxic radioactive elements). The MBL had to set up a process, with full metrological traceability, to guarantee the accuracy of the measurement results.

The measurement result expressed in becquerels depends on numerous parameters, unlike most other biology measurements (direct relationship between optical density and concentration). Indeed, the result depends directly on the detector resolution, background noise during measuring and the efficiency (or output) of the detectors.

The detector's efficiency depends not only on the energy of the $\gamma$ or X-ray (and therefore of the radioactive element sought), but also on the geometry of the measured system. The latter point shows the difficulty of metrological monitoring which depends on each individual measured: efficiency calibration is the most difficult step from a metrological point of view. The geometry of the standard and the radioelements used is critical to having an appropriate measurement range. A standard is required which closely resembles a standard human body containing the radioelements which are likely to be encountered during an examination by the company doctor. The MBL chose to use consensus (or phantom) standards recognized by experts in the field and according to the requirements of standards [22,23]: IGOR phantom for whole body measurements and LIVERMORE phantom for lung measurements. The measuring time per standard and radioelement, data processing and the cost of standards in order to obtain the calibration curve oblige the MBL to keep these calibrations for as long as possible and set up very strict metrological monitoring: monitoring of background noise (daily, monthly, average, annual by calculating the detection limit), monitoring of energy calibration (daily, annual), monitoring of detector resolution calibration (daily, annual), monitoring of efficiency calibration in a simple geometry to check the activity calculation (daily). This monitoring is recorded on control cards and Westgard rules $1_{2 s}, 1_{3 s}, 2_{2 s}, 10_{x}$ are applied.

At the same time as these daily checks which indirectly allow the metrological confirmation of the measurement system, the MBL carries out annual checks in the two geometries with: a LIVERMORE phantom different from the one used for calibration thanks to a loan from another CEA MBL and a SCHMIER phantom, another consensus standard, manufactured in the same MBL. Energy and resolution calibrations are also checked with these phantoms with identical acceptance criteria to those described above during daily checks. The efficiency and therefore the activity of the phantom is compared with the maximum tolerated deviations defined by the measurement uncertainty calculation according to the process described in standards NF S 92501 and NF S 92502. 


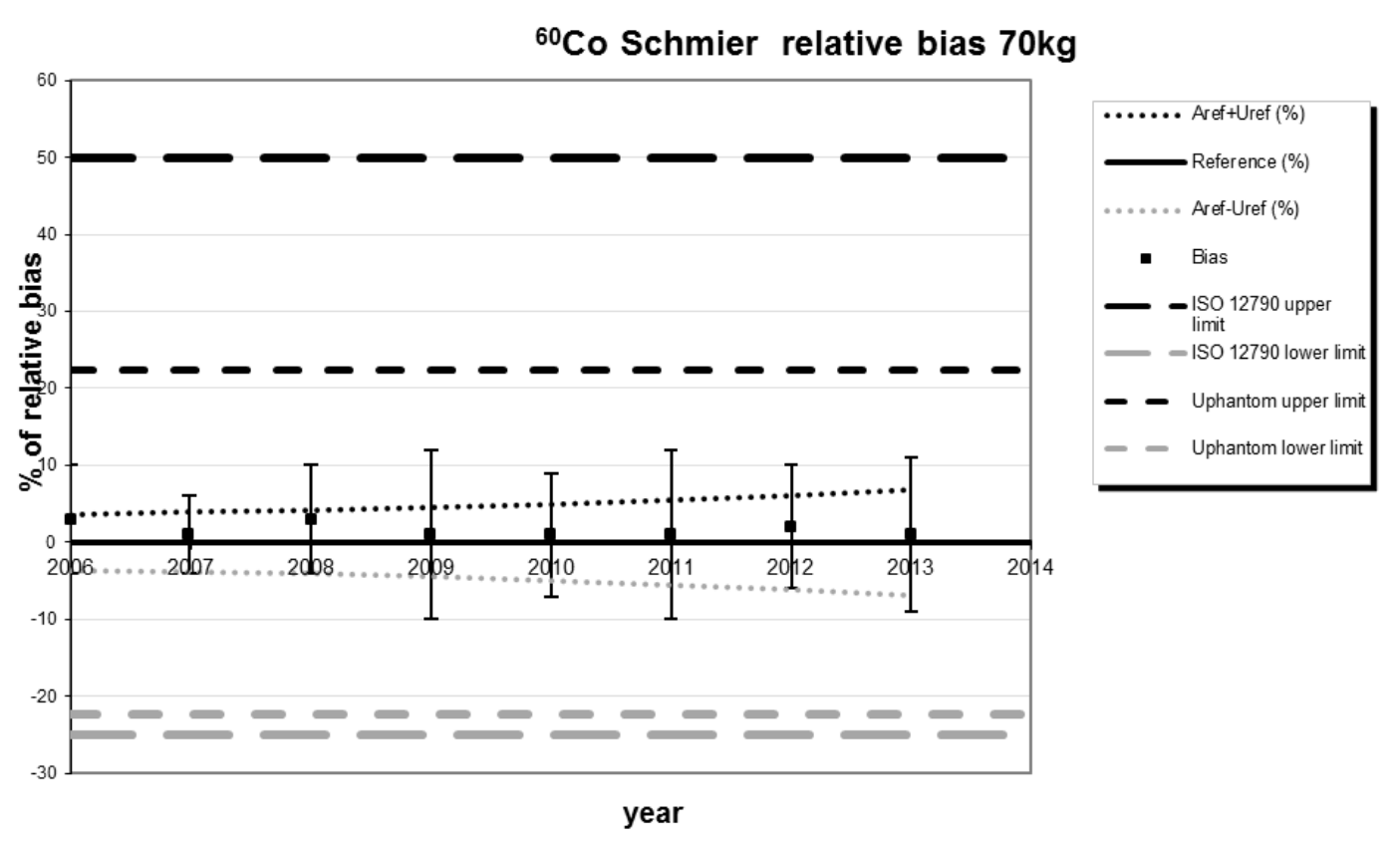

Fig. 13. Schmier relative bias $70 \mathrm{~kg}$.

The annual checks are recorded on monitoring cards (Fig. 13). As shown in this figure, the stability of efficiency calibration is confirmed.

The MBL participates in EQAs which the IRSN (French Institute for Radiological Protection and Nuclear Safety) alone organizes every three years. The results obtained by our MBL enable us to conclude the metrological confirmation of our anthroporadiometric system.

\section{Medical biology certified standards: reality in 2014?}

The development of the accreditation process in the MBLs, the wide variety of analyses measured in the MBLs, the high number of measuring methods which can be used for a given analysis and the need for the doctor and the patients to have comparability of analyses over time have prompted the development of initiatives to address this complex question. One response was the creation of the Joint Committee for Traceability in Laboratory Medicine in 2002 by the Comité International des Poids et Mesures (CIPM), the International Federation for Clinical Chemistry and Laboratory Medecine (IFCC) and the International Laboratory Accreditation Cooperation (ILAC). The JCTLM drew up a list of reference materials and identified reference laboratories.

This keeps MBLs informed of existing reference materials, methods and the reference laboratory.

In France, the Laboratoire National d'Essai (LNE), in collaboration with biologists from accredited laboratories, is working to provide reference materials. The LNE was listed by the JCTLM as a reference laboratory for measuring total cholesterol, glucose and blood creatinine. The LNE is developing a certified reference material for these three measurands. MBLs and also organizations which conduct intercomparison tests and in vitro diagnostic manufacturers may have reference materials to increase the accuracy of medical biology measurement results.

\section{Conclusion}

The aim of the authors of this article was to present the difficulties encountered in carrying out metrological confirmation and traceability in an MBL accredited according to standard NF EN ISO 15189 and the solutions put in place to remedy them.

Changes have had to be made to the analytical culture. Thanks to the collaborative work between biology, quality assurance and metrology professionals, MBLs in general and ours in particular have been able to make progress in terms of measurement traceability and technical personnel competence. The MBL was able to put in place the recommended process for metrological control, constantly bearing in mind the quality of results to meet the needs of the patient and the MBL's contribution to making clinical decisions. Future access to certified reference materials for a large number of analyses measured in medical biology will help accredited MBLs in their continuous improvement approach, particularly in the field of metrological traceability.

\section{References}

1. Guide de Bonne Exécution des Analyses (GBEA) Arrêté du 26 novembre 1994, Journal Officiel de la République Française II, 3 (1999)

2. Loi No. 2013-442 du 30 mai 2013 portant réforme de la biologie médicale. Journal Officiel de la République Française (2013) 
3. NF EN ISO 15189, Laboratoires de biologie médicale Exigence concernant la qualité et la compétence (2012)

4. NF EN ISO 10012, Système de management de la mesureExigences pour les processus et les équipements de mesures

5. COFRAC, Recueil des exigences spécifiques pour l'accréditation du laboratoire de biologie médicale. Document SH REF 02 Révision (2013)

6. NF EN ISO CEI 17025, Exigences générales concernant la compétence du laboratoire d'étalonnage et d'essais

7. Arrêté du 15 décembre 2009 relatif aux contrôles du respect des valeurs limites biologiques fixées à l'article R.4412-152 du Code du Travail pour les travailleurs exposés au plomb et à ses composés et aux conditions d'accréditation des laboratoires chargés des analyses. Journal Officiel de la République Française No. 0292 du 17 décembre 2009, p. 21766, texte No. 36

8. NF ISO 12790-1, Radioprotection - Critères de performances pour l'analyse radiotoxicologique. Partie 1: principes généraux (2002)

9. A. Vassault, D. Grafmeyer, J. de Graeve, R. Cohen, A. Beaudonnet, J. Bienvenu, Analyses de biologie médicale: Spécification et normes d'acceptabilité à l'usage de la validation de techniques. Annales Biologie Cliniques 57, 685695 (1999)

10. C. Ricos, V. Alvarez, F. Cava, J.V. Garcia-Lario, A. Hernandez, C.V. Jimenez, J. Minchinela, C. Perich, M. Simon, Current databases on biologic variation: pros, cons and progress, Scand. J. Clin. Lab. Invest. 59, 491-500 (1999)

11. J. Minchinella, C. Ricos, C. Perich, P. Fernandez-Calle, V. Alvarez, M. Domenech, M. Simon, C. Biosca, B. Boned, F. Cava, J.V. Garcia-Lario, M.P. Fernandez-Fernandes, Biological variation database and quality specifications for imprecision, bios and total error (desirable and minimum). The 2014 update. http://www.westgard.com/ biodatabase-2014-update.htm

12. Guide de métrologie à l'usage des laboratoires d'Analyses de Biologie médicale. Collège Français de Métrologie

13. M. Dumontet, Problématique de la maitrise métrologique des instruments d'analyses automatiques, Spectra Biologie 147, 35-39 (2005)

14. Directive 98/79/CE du parlement européen et du conseil du 27 octobre 1998, relative aux dispositifs médicaux de diagnostic in vitro, Journal Officiel des Communautés Européennes 7.12.98, L 331-1 à L331-37
15. COFRAC, Guide technique d'accréditation de vérification (portée A)/validation (portée B) des méthodes en biologie médicale. Document SH GTA 04 Révision (2011)

16. COFRAC, Guide technique d'accréditation Incertitudes en biologie médicale. Document SH GTA 14 Révision (2011)

17. COFRAC, Fiche type quantitatif vérification (portée A)/validation (portée B) d'une méthode de biologie médicale. Document SH FORM 43 Révision (2011)

18. COFRAC, Guide technique d'accréditation: contrôle de qualité en biologie médicale. Document SH GTA 06 Révision (2012)

19. J.O. Westgard, P.L. Barry, M.R. Hunt, T. Groth, A multirule Shewart chart for quality control in clinical chemistry, Clin. Chem. 27, 493-501 (1981)

20. NF EN IOS CEI 17043, Evaluation de la conformité. Exigences générales pour les essais d'aptitude (comparaison interlaboratoires)

21. NF ISO13528, Méthodes statistiques utilisées dans les essais d'aptitude par comparaison interlaboratoire

22. NF S 92501, Laboratoire de biologie médicale. Mesures anthroporadiométriques. Corps entier. Mesures des émissions gamma supérieures à $200 \mathrm{keV}$ (2013)

23. NF S 925012, Laboratoire de biologie médicale. Mesures anthroporadiométriques. Pulmonaire. Mesures des émissions gamma inférieures à $200 \mathrm{keV}$ (2013)

24. M. Dumontet, I. Fuss-Ohlen, J.L. Beaudeux, A. Perrin, A. Vassault, C. Giroud, G. Le Moel, F. Guitel, S. Ziani, S. Zerah, S. Robineau, F. Braconnier, Présentation à l'usage des Laboratoires d'analyses de biologie médicale des normes de métrologie (Document A), Ann. Biol. Clin. 62, 121-125 (2004)

25. M. Dumontet, A. Vassault, I. Fuss-Ohlen, F. Guitel, A. Perrin, C. Giroud, S. Robineau, F. Braconnier, J.L. Beaudeux, G. Le Moel, Recommandation pour l'installation dans le laboratoire de la fonction métrologie et de la documentation correspondante (Document B), Ann. Biol. Clin. 62, 479-486 (2004)

26. M. Dumontet, C. Giroud, A. Vassault, F. Guitel, A. Perrin, F. Braconnier, G. Férard, J.L. Beaudeux, Recommandations pour la maitrise des équipements de mesure au laboratoire d'analyses de biologie médicale (Document D), Ann. Biol. Clin. 67, 465-476 (2009)

27. Haute Autorité de Santé, Guide affection longue durée. Diabète de type 2 (2007) 